\title{
XXXVI. STUDIES ON CHLOROPLASTS
}

\section{SEPARATION OF CHLOROPLASTS, A STUDY OF FACTORS AFFECTING THEIR FLOCCULATION AND THE CALCULATION OF THE CHLOROPLAST CONTENT OF LEAF TISSUE FROM CHEMICAL ANALYSIS ${ }^{1}$}

\author{
BY ARTHUR CHARLES NEISH \\ From the Department of Chemistry, Macdonald College, McGill University, \\ Quebec, Canada
}

(Received 17 December 1938)

A NUMBER of references to experiments conducted with isolated chloroplasts are to be found in the literature. Englemann [1881] detected the evolution of oxygen by isolated chloroplasts and Ewart [1896] observed that they maintained their activity for some time after removal from the cell. Chloroplasts have been isolated from Stellaria media by Hill [1937] and from the leaves of the tomato plant by Granick [1937]. Noack [1927] obtained disintegrated chloroplasts by fractional centrifuging of green leaves ground with $\mathrm{CaCO}_{3}$ and Lubimenko [1929] employed autolysis to decompose cytoplasmic material. All of these workers had been concerned primarily with studies which required relatively small numbers of chloroplasts, and in most instances the details of the method of isolation were omitted.

The isolation of chloroplasts in large quantities would allow the study of their chemical structure and of the distribution of metabolites in the leaf. A study of photosynthesis by isolated chloroplasts could be carried out on a large scale and the problem of the photosynthesis of sugars by the plant attacked from this angle.

A procedure has been developed which gives a good yield of chloroplast substance suitable for chemical studies and also a slightly different procedure which gives morphologically intact chloroplasts.

After this work was completed Menke [1938] described the separation of the leaf tissue of Spinacia oleracea into four fractions, namely, cell wall, cytoplasm, water-soluble and chloroplast substances. This method is similar in principle to the one described herein, but is less convenient to use when only the chloroplast substance is desired. He does not give evidence for the chloroplasts being morphologically intact in his preparations. More recently Granick [1938] has described a similar method which gives morphologically intact chloroplasts.

Since the method of separating chloroplast granules depends on their flocculation, a study of the factors influencing the rate and degree of flocculation has been made. A knowledge of the percentage of the dry weight of leaf tissue which is contributed by chloroplasts is desirable in any study of the distribution of metabolites in leaf tissue. The chloroplast content of various leaves has been determined directly by weighing the chloroplast substance separated from a known amount of leaf tissue and indirectly by calculation from the analyses of

1 Macdonald College Journal Series No. 108. 
the chloroplast substance and corresponding leaf tissue for chlorophyll, carotene and xanthophyll which are known to be present only in the chloroplasts. The results obtained are discussed with reference to the relative ease of extraction of the plastid pigments and the condition of the plastid pigments in the chloroplasts.

\section{EXPERIMENTAL}

Chloroplasts exhibit osmotic properties similar to those of cells. The evidence for the existence of an osmotically active membrane surrounding the chloroplasts has been reviewed by Weier [1938]. Observations, in this connexion, have been made in order to determine the effect on the chloroplasts of the medium used in their isolation.

Chloroplasts (Trifolium pratense) swell and disintegrate after a few minutes in distilled water. The swollen chloroplast becomes vacuolated and appears granular in structure. These granules are discoid or spherical, green in colour and have a smooth surface. They appear to be optically homogeneous chloroplasts but are about one-sixth of the size of normal chloroplasts. The granules also swell and become vacuolated in distilled water but much more slowly than chloroplasts. They may stand in distilled water for several weeks without rupturing. When chloroplasts are isolated with distilled water the material so obtained is made up chiefly of these granules, which may therefore be regarded as intact bodies representing the chlorophyllous structure of the cell. When $0.5 M$ glucose or sucrose solutions are used instead of distilled water the chloroplasts do not all disintegrate and the preparations obtained consist of intact chloroplasts as well as free granules. There is no special advantage in using these sugar solutions when one is isolating the chloroplast substance for chemical studies, the object of which is to determine the nature of the medium in which the photosynthesis of carbohydrates occurs. The analysis of these granules, which are probably the ultimate seat of photosynthesis, should provide the desired information. A method has been evolved which enables one worker to prepare 2-3 g. (dry wt. basis) of the chloroplast substance per day.

The principles on which this method is based are as follows. (a) If leaf tissue is ground in a mortar, without the addition of any other solid substance to act as a grinding agent, the cells will be ruptured, freeing the chloroplasts. (b) Starch grains are larger and denser than chloroplasts and may be separated from chloroplasts by centrifuging the suspension at.a controlled speed. Only a few of the chloroplasts will be removed by this treatment. (c) Chloroplast granules in suspension may be flocculated by ions such as $\mathrm{Ca}^{++}$and $\mathrm{Mg}^{++}$and when flocculated they settle by gravitation.

The exact details of the method vary with the material. Four species have been employed successfully, namely Trifolium pratense (red clover), Elodea canadensis, Arctium minus (common burdock) and Onoclea sensibilis (sensitive fern). Species with fibrous leaves such as Agropyron repens (couch grass), or mucilaginous leaves such as the young leaves of Tilia glabra (basswood) do not provide suitable material. In preparing the sample as much fibrous material as possible should be removed, e.g. with red clover the three leaflets are taken by breaking at the point where they join together; with Elodea the bushy, green tips are taken; with burdock, the large midrib is removed from the leaf and with Onoclea the leaflets of the fronds are broken off about half an inch from the petiole.

After washing the leaves in distilled water and squeezing by hand to remove excess water, about $20 \mathrm{~g}$. of the compressed material are sliced with scissors into 
an 8 in. porcelain mortar and pounded to a pulp. About $200 \mathrm{ml}$. of distilled water are added, in three portions, and the pulp ground after each addition. This gives a suspension of free chloroplast granules in the diluted cytoplasm. Most of the fibre and unground material is next removed by filtering the suspension through bolting-silk (200-mesh) and squeezing the cloth. The suspension is now centrifuged in $250 \mathrm{ml}$. cups at 2000 r.p.m. In the case of the sensitive fern it is necessary to reduce the speed of centrifuging since the chloroplasts are larger and contain starch. The purpose of this treatment is to remove the starch grains which sediment at a much lower speed than do the chloroplasts. Some of the chloroplast granules will be carried down with the starch granules'. The supernatant suspensions are decanted into a l-litre measuring cylinder until $950 \mathrm{ml}$. are obtained, $2 M \mathrm{CaCl}_{2}$ solution is added to the $1000 \mathrm{ml}$. mark and the contents of the cylinder mixed by inverting several times. The suspension is kept for about $30 \mathrm{~min}$. when the flocculated chloroplast granules will have settled to about the $200 \mathrm{ml}$. mark. The supernatant liquid is now decanted or siphoned off; the flocculated chloroplast granules centrifuged at the same speed as before; the supernatant liquid decanted and the chloroplast granules triturated with distilled water using a glass rod with a rubber policeman. The centrifuging and washing of the chloroplast granules is repeated, usually three times, until the concentration of the flocculant is reduced to such a degree that the chloroplast granules start again to disperse. Probably only a trace of the flocculant remains at this stage. The material in the bottom of the centrifuge tube may be dried in vacuo at $60^{\circ}$ for chemical analysis or redispersed if it is desired to determine enzymic activity. This material is a healthy green colour and appears to be fairly free from foreign material such as starch grains, nuclear material and cell wall fragments.

If intact chloroplasts are desired $0.5 \mathrm{M}$ glucose can be used instead of distilled water and the chloroplasts centrifuged out at a high speed, without using a flocculating agent. This method can easily be modified to conform with the procedure of Menke [1938] for recovering cytoplasmic, water-soluble and cell wall material.

\section{The factors influencing the rate of flocculation of the chloroplast substance in suspension}

Many tests were carried out simultaneously, in all of which $10 \mathrm{ml}$. of the suspension of chloroplast substance, usually from red clover, were mixed with $10 \mathrm{ml}$. of a solution of the flocculant being tested. Unless otherwise stated the final concentration of the flocculant, after mixing, was always $0 \cdot 1 M$. The results of these experiments and the inferences drawn therefrom may be summarized as follows.

A. The rate and degree of flocculation were found to be the same with $\mathrm{MgCl}_{2}, \mathrm{Mg}\left(\mathrm{NO}_{3}\right)_{2}$ and $\mathrm{MgSO}_{4}$; therefore the activity was due to the cation.

B. The rate of flocculation depended on the species of cation used.

Group 1. Cations which gave a good flocculation in $1 \mathrm{~min}$.

$$
\mathrm{Ag}^{+}>\mathrm{Pb}^{++}>\mathrm{Fe}^{++}
$$

Group 2. Cations which required about $15 \mathrm{~min}$. to give the same degree of flocculation as Group 1.

$$
\mathrm{Co}^{++}, \mathrm{Cu}^{++}>\mathrm{Zn}^{++}, \mathrm{Cd}>\mathrm{Sn}^{+++}>\mathrm{Mg}^{++}, \mathrm{Ba}^{++}, \mathrm{Ca}^{++}, \mathrm{Mn}^{++}
$$

Group C. Cations which gave very little flocculation in $24 \mathrm{hr}$.

$$
\mathrm{Sn}^{++++}>\mathrm{Fe}^{+++}>\mathrm{Al}^{+++}>\mathrm{Na}^{+}, \mathrm{K}^{+}, \mathrm{NH}_{4}^{+}
$$


C. The suspensions are flocculated by hydrogen ions and the rate at which they flocculate depends, in some cases, upon the $p \mathrm{H}$. When $\mathrm{HCl}$ or phosphate buffer solutions are used as flocculants the chloroplast substances of Trifolium

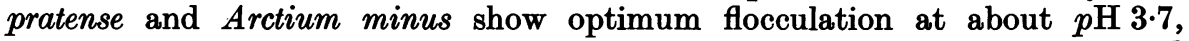
whereas the chloroplast substances of Onoclea sensibilis, Elodea canadensis and Solidago sp. show no such optimum and may be flocculated with equal facility at $p \mathrm{H} 5.5$ and $p \mathrm{H} 2.0$ or even when suspended in $2 N \mathrm{HCl}$.

D. The flocculating power of a salt solution cannot be explained as being due entirely to a favourable $p \mathrm{H}$. At $p \mathrm{H} \mathrm{6.0} \mathrm{the} \mathrm{rate} \mathrm{of} \mathrm{flocculation} \mathrm{of} \mathrm{suspensions} \mathrm{of}$ Trifolium chloroplasts decreased with decreasing concentrations of $\mathrm{CaCl}_{2}$ $(0 \cdot 1-0 \cdot 0005 M)$. However, $\mathrm{CaCl}_{2}$ and $\mathrm{FeCl}_{2}$ at the same concentration were much better flocculants at $p \mathrm{H} 3 \cdot 0-3 \cdot 2$ than at $p \mathrm{H} \mathrm{4 \cdot 3-4.9}$, whereas the flocculating power of $\mathrm{AgNO}_{3}$ was equally good in both ranges of $p \mathrm{H}$.

Electrophoresis of a suspension of Trifolium chloroplast granules showed the chloroplast granules to be electrically charged, their mobility depending upon the $p \mathrm{H}$. In $0.2 \mathrm{~N} \mathrm{HCl}$ the chloroplast substance was positively charged and in distilled water it was negatively charged. In these respects, then, the behaviour of Trifolium chloroplasts was analogous to that of protein molecules with an isoelectric point about $p H$ 3.7. The resemblance of the flocculation of the chloroplast substance to the precipitation of proteins was shown by Noack [1927] who observed their "salting out" by $\left(\mathrm{NH}_{4}\right)_{2} \mathrm{SO}_{4}$. The amphoteric nature of the chloroplast substance was not, however, the same in different plants, as it was not shown by the chloroplast substance of Onoclea sensibilis, which, like that of Trifolium pratense, contains large amounts of protein.

Flocculation by salts such as $\mathrm{CaCl}_{2}$ and $\mathrm{Mg}\left(\mathrm{NO}_{3}\right)_{2}$ was reversible. If the flocculant was washed out the chloroplast substance dispersed again and the process could be repeated. $\mathrm{Fe}^{+++}$and $\mathrm{Al}^{+++}$were very poor flocculants whereas $\mathrm{Fe}^{++}$and $\mathrm{Ag}^{+}$were excellent flocculants. The failure of trivalent ions to cause flocculation might have been due to the fact that they were present in sufficient concentration to reverse the charge. That such was not the case was indicated by the fact that negligible flocculation was obtained with varying concentrations of $\mathrm{FeCl}_{3}(M / 12-M / 394)$ and $\mathrm{AlCl}_{3}(M / 20-M / 740)$. It was of interest to note that the chloroplast substance prepared from red clover which was growing in the autumn and had been exposed to frost, flocculated almost as well with $\mathrm{AlCl}_{3}$ as with $\mathrm{CaCl}_{2}$. Silver was the only univalent ion which was a good flocculant. It was reduced by the ascorbic acid contained in the chloroplast. Presumably, therefore, the reduction of $\mathrm{Ag}^{+}$removes electrons from the chloroplast substance thus reducing the negative charge and causing flocculation. The flocculating power of an ion may therefore depend on several factors such as electrical charge, age of chloroplast, solubility of a protein or lipin salt, or on some specific reaction between the ion and a constituent of the chloroplast.

\section{The calculation of the chloroplast content of leaf tissue}

The chloroplast content of leaf tissue may, theoretically, be determined in two ways: $(a)$ by weighing the chloroplast substance separated as quantitatively as possible from a known amount of leaf tissue; $(b)$ by analysing the chloroplasts and corresponding leaf tissue for some substance known to be found only in the chloroplasts, such as chlorophyll, carotene or xanthophyll. If, for example, $0.1 \mathrm{~g}$. of leaf tissue gives a chlorophyll extract the colour of which is one-third the intensity of that derived from the same weight of chloroplast substance prepared from the same leaf tissue, then one-third of that leaf tissue is composed of chloroplasts. Obviously the first procedure will give the minimum value since 
it is difficult to get all of the chloroplasts out of a given quantity of leaf tissue and since some of the chloroplast substance sediments out with the starch grains.

The values derived by different methods for the chloroplast content of the same leaf tissue are shown in Table I, and for different leaf tissues in Table II.

Table I. Chloroplast content of red clover leaf tissue, as derived by different methods

Method employed
Isolation and weighing
Free chlorophyll (acetone extract)
Bound chlorophyll (acetone extract)
Carotene + xanthophyll
Carotene alone
Xanthophyll alone
Total chlorophyll (HCl treatment)

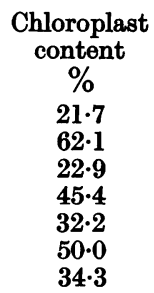

Table II. Chloroplast content $(\%)$ of the leaf tissues of different plants, as derived by different methods

\begin{tabular}{|c|c|c|c|c|}
\hline Species & $\begin{array}{l}\text { From } \\
\text { carotene } \\
\text { content }\end{array}$ & $\begin{array}{c}\text { From } \\
\text { chlorophyll } \\
\text { (HCl treatment) }\end{array}$ & $\begin{array}{c}\text { From } \\
\text { xanthophyll } \\
\text { content }\end{array}$ & $\begin{array}{c}\text { From } \\
\text { isolation } \\
\text { and weighing }\end{array}$ \\
\hline $\begin{array}{l}\text { Trifolium pratense* } \\
\text { Trifolium pratense* } \\
\text { Trifolium pratense* } \\
\text { Elodea canadensis } \\
\text { Onoclea sensibilis } \\
\text { Articum minus }\end{array}$ & $\begin{array}{l}32 \cdot 2 \\
31 \cdot 1 \\
26 \cdot 3 \\
16 \cdot 6 \\
36 \cdot 9 \\
33 \cdot 9\end{array}$ & $\begin{array}{l}34 \cdot 3 \\
31 \cdot 4 \\
25 \cdot 0 \\
36 \cdot 1 \\
\overline{33 \cdot 3}\end{array}$ & $\begin{array}{l}50 \cdot 0 \\
50 \cdot 0 \\
41 \cdot 4 \\
10 \cdot 0 \\
37 \cdot 4 \\
54 \cdot 1\end{array}$ & $\begin{array}{l}21 \cdot 7 \\
- \\
30 \cdot 9 \\
13 \cdot 1 \\
10 \cdot 7\end{array}$ \\
\hline
\end{tabular}

The terms "free" and "bound" chlorophyll require some explanation. A chloroplast preparation was suspended in an $85 \%$ solution of acetone in a Büchner funnel fitted with filter paper; after a few minutes suction was applied. The extraction of chlorophyll with $85 \%$ acetone was repeated until the extract was colourless, and then the residue was extracted repeatedly and in the same manner with $10 \%$ trichloroacetic acid. A yellow pigment was removed by this treatment. If the trichloroacetic acid extraction were now followed by further extractions with $85 \%$ acetone the extracts contained considerable quantities of green pigment. The pigment thus extracted showed the typical red fluorescence of chlorophyll dissolved in acetone; it was found in whole leaf tissue and the chloroplast substance and was designated as "bound" chlorophyll.

Total chlorophyll was determined by treatment with $\mathrm{HCl}$ as follows: $0 \cdot 1 \mathrm{~g}$. portions of dried and thoroughly ground tissue were weighed into $50 \mathrm{ml}$. centrifuge bottles and extracted with $10 \mathrm{ml}$. of water by heating in a boiling water bath for about $10 \mathrm{~min}$., centrifuging and decanting the supernatant liquid. This removed a brown pigment from the whole leaf tissue which interfered with the determinations. After the removal of this pigment the remainder of the procedure was carried out, simultaneously and in identical manner, with an equal weight of chloroplasts and leaf tissue, as follows: $10 \mathrm{ml}$. of $6 \mathrm{~N} \mathrm{HCl}$ were added, the suspension was heated on a boiling water bath for a few min., centrifuged and the supernatant liquid containing the green-coloured products of chlorophyll hydrolysis was decanted through filter paper into a $25 \mathrm{ml}$. glass-stoppered 
graduated cylinder. The extraction was repeated using $5 \mathrm{ml}$. of $\mathrm{HCl}$, each time, until all the green pigment had been extracted. The combined extracts were mixed and the colour of the extract from the chloroplasts compared with that from the corresponding leaf tissue. The more intensely coloured extract was diluted until, on visual comparison, the colours of the two solutions appeared to be of equal intensity. The relative volumes were noted from which the chloroplast content of the leaf tissue was calculated.

Carotene and xanthophyll determinations were carried out by weighing $0 \cdot 1 \mathrm{~g}$. of the dried and ground tissue into a $50 \mathrm{ml}$. centrifuge bottle and adding $3 \mathrm{ml}$. of $30 \% \mathrm{KOH}$ in absolute methyl alcohol and $20 \mathrm{ml}$. of light petroleum. The bottles were then stoppered and shaken for $5 \mathrm{~min}$. in a mechanical shaker, centrifuged and the supernatant liquid siphoned off into separating funnels. The process was repeated, until no more pigment was extracted, using $10 \mathrm{ml}$. of light petroleum and $1 \mathrm{ml}$. of alcoholic $\mathrm{KOH}$. The addition of a small amount of water was sometimes helpful. The carotene and xanthophyll contained in the combined petroleum extracts were separated by extraction with $85 \%$ methyl alcohol. The carotene content of the petroleum solution and the xanthophyll content of the methyl alcohol solution were determined by using an Evelyn photoelectric colorimeter and referring to a standard calibration curve prepared from pure $\beta$-carotene.

The results obtained from the chlorophyll determinations by $\mathrm{HCl}$ treatment and from the carotene determinations compare well and appear to represent the true values (see Table II). The only exception is Elodea canadensis where the value derived from carotene is obviously wrong, being lower than the figure obtained by isolation and weighing. The latter values are always low but not to the same extent with different species. A smaller fraction of the total number of chloroplasts is obtained in species with fibrous leaves, such as Arctium and Onoclea than in species with non-fibrous leaves such as Elodea. The chloroplast content of Onoclea sensibilis could not be estimated from chlorophyll determinations by $\mathrm{HCl}$ treatment because of the presence in the extract of the whole leaf tissue of a pink colour which interfered with the colorimetry.

The values shown in Tables I and II indicate the difficulties to be encountered in the extraction of the plastid pigments. If, for example, a value higher than the true value for the chloroplast content is obtained, as is the case in the calculation of the chloroplast content of the leaves of Trifolium pratense from xanthophyll determinations, then this means that relatively more xanthophyll has been extracted from the whole leaf than from the chloroplast substance. If the value is too low, as in the case of Elodea canadensis, then the reverse holds. The results in Table I show that chlorophyll and xanthophyll are extracted with difficulty from Trifolium chloroplast substance by $85 \%$ acetone. Carotene is apparently extracted with equal facility from the chloroplast substance and whole leaf tissue. Both carotene and xanthophyll are more easily extracted from the chloroplast substance of Elodea than from the whole leaf tissue, etc. Since the green chlorophyll derivatives obtained by the $\mathrm{HCl}$ treatment are extracted with equal ease from the chloroplast substance and whole leaf tissue in all cases, this appears to be the most dependable method to employ.

The differences in the ease of extraction of the plastid pigments from the chloroplasts as compared with the whole leaf tissue of the same species and as contrasted with other species, can apparently be explained only by assuming the presence of other concomitant substances which condition their solubility. This view was held by Willstatter. According to Lubimenko [1929] chlorophyll $a$ and $b$, carotene and xanthophylls exist in the leaf in combination with protein in the 
form of a single complex pigment molecule which shows slight variations in complexity in different species. We have observed that a purified chlorophyll preparation on treatment with $\mathrm{HCl}$ in the manner already described yields no green-coloured derivatives and that the addition of this chlorophyll preparation to chloroplasts does not increase the amount of green pigment extracted with $\mathrm{HCl}$ over that obtained from the chloroplasts alone. These observations are interpreted as showing that chlorophyll, as it exists in the chloroplast, perhaps in the complex pigment of Lubimenko, is decomposed by $\mathrm{HCl}$ treatment in a different manner from chlorophyll which has been extracted by acetone and freed from carotenoid pigments.

\section{SUMMaRY}

A method which enables one worker to isolate chloroplasts from leaf tissue at the rate of $2-3 \mathrm{~g}$. daily has been described.

The chloroplast substance in suspension is charged; the charge depends on the $p \mathrm{H}$ being negative above $p \mathrm{H} \mathrm{3.7}$. Various cations cause the flocculation of these suspensions. This flocculation cannot be explained as a simple electrical neutralization of charges; evidently specific reactions may occur between the chloroplast substance and certain cations which are responsible for the anomalies noted. The age of the chloroplast may have some effect.

Several methods for calculating the chloroplast content of leaf tissue have been worked out and compared. These methods are based on analysis for the

plastid pigments. The results obtained show that completeness of extraction of these pigments is affected by the presence of unknown substances. A simple method based on analysis for chlorophyll gives satisfactory results in most cases.

I wish to express my thanks to Dr W. D. McFarlane for the facilities extended, for helpful criticism and for assistance in preparing the manuscript.

\section{REFERENCES}

Englemann (1881). Bot. Ztg. 39, 446.

Ewart (1896). J. linn. Soc. 31, 364.

Granick (1937). Abstracts of 14th Annual Meeting of Am. Soc. of Plant Physiologists, 28-30 Dec.

- (1938). Amer. J. Bot. 25, 558.

Hill (1937). Nature, Lond., 139, 881.

Lubimenko (1929). Cited by J. H. Priestly, New Phytol. 28, 197.

Menke (1938). Z. Bot. 32, 273.

Noack (1927). Biochem. Z. 183, 135.

Weier (1938). Bot. Rev. 4, 475. 